\section{What is already known on this topic}

Worldwide, few potentially eligible patients are approached about entry into clinical trials; healthcare professionals find discussing trials and obtaining truly informed consent difficult

Patients are often confused or unclear about the experimental nature of treatment in trials

\section{What this study adds}

A training course was designed specifically to help health professionals provide clear information about phase III randomised trials of cancer treatments to patients and to encourage them to approach all eligible patients for recruitment

The course increased participants' reported self confidence about recruiting patients into trials, and objective analyses revealed improvements in the style and content of the participants' discussions

focus on their own perceived areas of difficulty and makes the course work pertinent to their needs. ${ }^{7}$

We have used these types of "trigger" tapes successfully in our previous research with nurses and doctors working in oncology. ${ }^{6} 7$ The intervention reported here was valued highly by all participants.

The positive findings from the course included an increase in participants' reported self confidence about recruiting patients into trials, and objective analyses revealed behavioural changes in the style and content of the participants' discussions. There is strong evidence that if both competence and self confidence are improved then behavioural changes often do transfer successfully into the clinical setting and endure, even without support or consolidation courses. ${ }^{78}$

Our training course is now being rolled out by the national cancer research networks in England and
Wales, and research to see if real patient outcomes are affected is planned.

We thank members of the NCRN Consumer Liaison Group for their generous contributions and agreement to be filmed together with Dr Rob Glynne Jones, Professor Robert Leonard, Professor Peter Selby, Professor Stephen Spiro, Professor Pierre Guillou, Dr David Bloomfield, Dr Fiona McKinna, Dr Joanne Simpson, nurse lead for the WCTN Libby Batt, trials manager Nicky Gower, and Louise Leach. Mark Mansell and Roland Brinton from Visual Image Publishing produced the series with us. Finally we thank Role Call actors, all the healthcare professionals who participated in the study, and members of Sussex Psychosocial Oncology Group who assisted in the smooth running of the courses, especially Sue Catt, Karen Nicholls, Val Shilling, Lou Atkins, Leigh Johnson, Mel Price, Tracy Woodcock, and Louise Leach.

Contributors: See bmj.com

Funding: Cancer Research UK funded the project, and AstraZeneca provided an unrestricted educational grant to help video production.

Competing interests: None declared.

Ethical approval: None required.

1 Department of Health. Government response to the sixth report of the House of Commons Science and Technology Committee: session 1999/2000 cancer Commons Science and Technology Committee: session
research-a fresh look. London: HMSO, 2000 (Cm 4928).

2 Albrecht TL, Blanchard C, Ruckdeschel JC, Coovert M, Strongbow R. Strategic physician communication and oncology clinical trials. J Clin Oncol 1999;17:3324-32.

3 Jenkins VA, Fallowfield LJ, Souhami A, Sawtell M. How do doctors explain randomised clinical trials to their patients? Eur J Cancer 1999;35:1187-93.

4 Pope JE, Tingey DP, Arnold JM, Hong P, Ouimet JM, Krizova A. Are subjects satisfied with the informed consent process? A survey of research participants. J Rheumatol 2003;30:815-24.

5 Donovan J. Mills N, Smith M, Brindle L, Jacoby A, Peters T, et al. Quality improvement report: Improving design and conduct of randomised trials improvement report: Improving design and conduct of randomised trials
by embedding them in qualitative research: ProtecT (prostate testing for by embedding them in qualitative research: ProtecT (prostate testing for
cancer and treatment) study. Commentary: Presenting unbiased information to patients can be difficult. BMJ 2002;325:766-70.

6 Fallowfield L, Saul J, Gilligan B. Teaching senior nurses how to teach communication skills in oncology. Cancer Nurs 2001;24:185-91.

7 Fallowfield L, Jenkins V, Farewell V, Saul J, Duffy A, Eves R. Efficacy of a Cancer Research UK communication skills training model for oncologists: a randomised controlled trial. Lancet 2002;359:650-6.

8 Fallowfield L, Jenkins V, Farewell V, Solis-Trapala I. Enduring impact of communication skills training: results of a 12-month follow-up. $\mathrm{Br} J$ Cancer 2003;89:1445-9.

(Accepted 10 January 2005)

doi $10.1136 /$ bmj.38366.562685.8F

\title{
Teaching of cultural diversity in medical schools in the United Kingdom and Republic of Ireland: cross sectional questionnaire survey
}

\author{
Nisha Dogra, Sue Connin, Paramjit Gill, John Spencer, Margot Turner
}

Over the past decade, pressure to teach about cultural diversity in the medical undergraduate curriculum has increased. ${ }^{12}$ Tomorrow's doctors states that "students should have acquired respect for patients and colleagues that encompasses, without prejudice, diversity of background and opportunity, language, culture and way of life." In this study, we used ethnicity as an example of cultural diversity, but we acknowledge the importance of other factors. We aimed to identify the extent to which cultural diversity was being taught in medical schools in the United Kingdom and Republic of Ireland.

\section{Participants, methods, and results}

We devised a study specific questionnaire that asked a series of closed questions plus some open ended questions inviting free text responses. We sent this to contacts in all medical schools in the United Kingdom and Republic of Ireland $(\mathrm{n}=31$ at the time of the study). We followed up non-respondents by a further letter and emails. We entered data into SPSS and did a content analysis of the free text responses.

This article was posted on bmj.com on 11 January 2005: http://bmj.com/ cgi/doi/10.1136/bmj.38338.661493.AE 
East Kent Hospitals

NHS Trust, Kent

Sue Conning

educational adviser

University of

Birmingham,

Birmingham

Paramjit Gill

clinical senior lecturer

in general practice

University of

Newcastle,

Newcastle upon

Tyne

John Spencer

professor in primary

care

St George's Medical

School, London

Margot Turner

community placement

developer

Correspondence to: N Dogra

nd13@le.ac.uk

Responses to yes/no item questions ( $n=30 / 31$; response rate=97\%). Values are numbers (percentages) *

\begin{tabular}{|c|c|c|c|c|}
\hline Item & Yes & No & Not applicable & Not known \\
\hline Does your school provide formal teaching in cultural diversity? & $23(72)$ & $7(22)$ & $2(6)$ & 0 \\
\hline Does your school provide formal teaching in cultural sensitivity/multicultural issues? & $26(81)$ & $6(19)$ & 0 & 0 \\
\hline Is the course a standalone course? & $5(16)$ & $21(66)$ & $6(19)$ & 0 \\
\hline Is it part of a larger course? & $23(72)$ & $2(6)$ & $7(22)$ & 0 \\
\hline Is the teaching part of the core curriculum? & $24(75)$ & $3(9)$ & $5(16)$ & 0 \\
\hline SSMs/SSCs & $16(50)$ & $11(34)$ & $5(16)$ & 0 \\
\hline Is student self study expected? & $18(56)$ & $8(25)$ & $5(16)$ & $1(3)$ \\
\hline Does formative or summative assessment take place? & $19(59)$ & $6(19)$ & $5(16)$ & $2(6)$ \\
\hline Formative & $9(28)$ & & & \\
\hline Summative & $10(31)$ & & & \\
\hline Is student feedback gathered? & $23(72)$ & $4(13)$ & $5(16)$ & 0 \\
\hline Is there teaching about specific ethnic groups? & $13(41)$ & $13(41)$ & $5(16)$ & $1(3)$ \\
\hline Are different ethnic groups used to plan teaching? & $20(63)$ & $5(16)$ & $6(19)$ & $1(3)$ \\
\hline Are different ethnic groups used to deliver teaching? & $18(56)$ & $6(19)$ & $7(22)$ & $1(3)$ \\
\hline Are there plans for further development? & $18(56)$ & $9(28)$ & Under development, 4 (13) & $1(3)$ \\
\hline
\end{tabular}

SSM=special study module; $\mathrm{SSC}=$ student selected component.

${ }^{*}$ Denominator for percentages is 32 , as two medical schools completed questionnaires for both their four year and five year programmes.

Thirty (97\%) medical schools responded to the questionnaires; 32 questionnaires were returned, as two medical schools completed questionnaires for both their four year and five year programmes. The table shows the items to which yes/no responses were possible.

\section{Teaching and assessment methods}

Fourteen (44\%) schools used three or fewer teaching methods, and 11 (34\%) used four or five methods. The most commonly used teaching methods were small group based teaching (21), discussions (16), lectures (16), problem based learning (11), community placements (9), and workshops (8).

Ten $(31 \%)$ respondents stated that their school used only one assessment method; six (19\%) respondents used two methods, and five $(16 \%)$ used three methods. Nine $(28 \%)$ respondents stated that the question was not applicable. The most commonly used methods were short answer questions (8 schools), essays (7), objective structured clinical examinations (6), and projects (5). Other assessment methods were used by three or fewer schools.

Thirteen $(41 \%)$ respondents stated that cultural diversity was integrated throughout the curriculum. Eight $(25 \%)$ respondents stated that cultural diversity was taught in the first year; we received one (3\%) positive response for each of years two, three, four, and five. Very positive or positive feedback was reported by 18 $(56 \%)$ respondents.

\section{Findings from the free text}

We identified the following themes from the free text comments: staff related factors (how staff were valued, as well as their difficulties in managing the organisa-

\section{What is already known on this topic}

Until recently, little attention has been paid to teaching medical students about cultural diversity

\section{What this study adds}

Teaching of cultural diversity is being developed but seems rather fragmented

Uncertainty remains as to what constitutes cultural diversity teaching tion and delivery of diversity teaching); students' perceptions and evaluation of courses; contents and organisation of the course (the time allocated, where the course was placed, and how teaching was organised); and delivery and outcomes of the course.

\section{Comment}

Some progress seems to have been made since the publication of a survey in $1995,{ }^{3}$ in that $72 \%$ of schools now report some teaching in cultural diversity. However, the number of respondents reporting that their school is teaching cultural diversity compares unfavourably with the United States, ${ }^{4}$ albeit more favourably than Canada. ${ }^{5}$ Teaching of cultural diversity has been developed in the United Kingdom but seems rather fragmented. A great deal of uncertainty seems to exist about what constitutes diversity teaching.

This study has limitations in that it was a questionnaire survey and the terminology used may not have matched the terminology of the schools. The staff who returned the questionnaires might not have been best placed to complete them. Nevertheless, the survey presents a snapshot of the state of teaching of cultural diversity in the United Kingdom and Republic of Ireland in 2003. Further work is needed to embed teaching of cultural diversity within the medical undergraduate curriculum and to ensure that it is valued by staff and students.

We thank all the staff who completed the questionnaires.

Contributors: All the authors contributed to the design and writing of the paper. ND did the analysis, wrote the first draft, and is the guarantor.

Funding: None.

Competing interests: None declared.

Ethical approval: Not needed.

1 General Medical Council. Tomorrow's doctors. London: General Medical Council, 1993

2 Gill PS, Green P. Learning for a multicultural society. Br J Gen Pract 1996;46:704-5.

Robins S. Multicultural health care: current practice and future policy in medical education. London: British Medical Association, 1995.

Flores G, Gee D, Kastner B. The teaching of cultural issues in US and Canadian medical schools. Acad Med 2000;75:451-5.

5 Azad N, Power B, Dollin J, Chery S. Cultural sensitivity training in Canadian medical schools. Acad Med 2002;77:222-8.

(Accepted 10 December 2004)

doi 10.1136/bmj.38338.661493.AE 